\title{
Snow Interception Modeling: Isolated Observations have led to Land Surface Models Lacking Appropriate Climate Sensitivities
}

\author{
Jessica Lundquist ${ }^{1}$, Susan Dickerson-Lange ${ }^{1}$, Ethan Gutmann ${ }^{2}$, Tobias Jonas ${ }^{3}$, Cassie \\ Lumbrazo $^{1}$, and Dylan Reynolds ${ }^{1}$ \\ ${ }^{1}$ University of Washington \\ ${ }^{2} \mathrm{NCAR}$ \\ ${ }^{3}$ WSL Institute for Snow and Avalanche Research SLF
}

February 27, 2021

\begin{abstract}
When formulating a hydrologic model, scientists rely on parameterizations of multiple processes based on field data, but literature review suggests that more frequently people select parameterizations that were included in pre-existing models rather than re-evaluating the underlying field experiments. Problems arise when limited field data exist, when "trusted" approaches do not get reevaluated, and when processes fundamentally change in different environments. The physics and dynamics of snow interception by conifers, including both loading and unloading of snow, is just such a case. The most commonly used interception parameterization is based on data from four trees from one site, but field study results are not directly transferable between environments. The process varies dramatically between locations with relatively warmer versus colder winters. Here, we combine a comprehensive literature review with a model to demonstrate essential improvements to model representations of snow interception. We recommend that, as a first and essential step, all models include increased loading due to increased adhesion and cohesion when temperatures rise from -3 and $0^{\circ} \mathrm{C}$. The commonly used parameters of a fixed maximum value for loading and an e-folding time for unloading are not supported by observations or physical understanding and are not necessary to reproduce observations. In addition to unloading based on physical processes, such as wind or canopy warming, all models must represent melting of in-canopy snow so that it can be unloaded in liquid form. As a second step, we propose field experiments across climates and forest types to investigate: a) a representation of the force balance between adhesion and cohesion versus gravity for both interception efficiency and rates of unloading, b) wind effects during and between storms, and c) lubrication when snow melts. For greatest impact, this framework requires dedicated field measurements. These processes are essential for models to accurately represent the impacts of dynamically changing forest cover and snow cover on both global albedo and water supplies.
\end{abstract}

\section{Hosted file}

Lundquist Snow Interception Modeling no figures.pdf available at https://authorea.com/users/ 398505/articles/511106-snow-interception-modeling-isolated-observations-have-led-toland-surface-models-lacking-appropriate-climate-sensitivities 


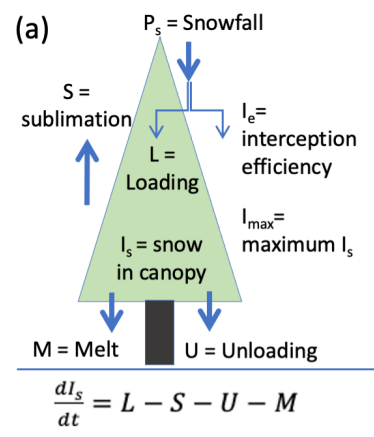

(c)

$$
\begin{gathered}
U=I_{S}\left(\frac{T_{\text {air }}}{C_{T}}+\frac{\text { wind }}{C_{V}}\right) \\
\text { or } \\
U=I_{S} C_{t d}
\end{gathered}
$$

(b)

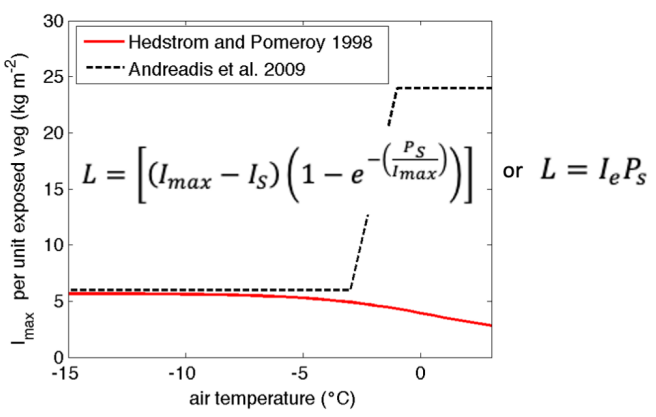

(d)

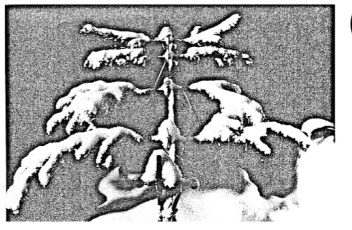

(e)

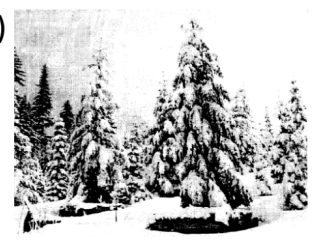

Schmidt and Gluns (1991) look at snow on a branch. At $\mathrm{T}_{\text {air }}<-3^{\circ} \mathrm{C}$, as the specific gravity of snow increases, bouncing of particles increases and interception decreases.

\section{Schmidt and Pomeroy (1990) look at branch stiffness. Branches bend more easily at warmer temperatures.}

Hedstrom and Pomeroy (1998) formulate interception as a function of density, parameterized by $T_{\text {air }}$. They cite Schmidt and Gluns (1991), but the numbers they use are from unpublished data.

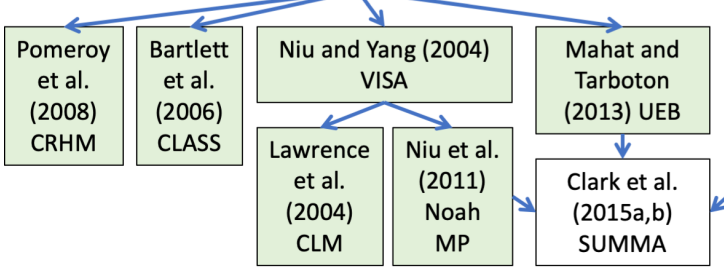

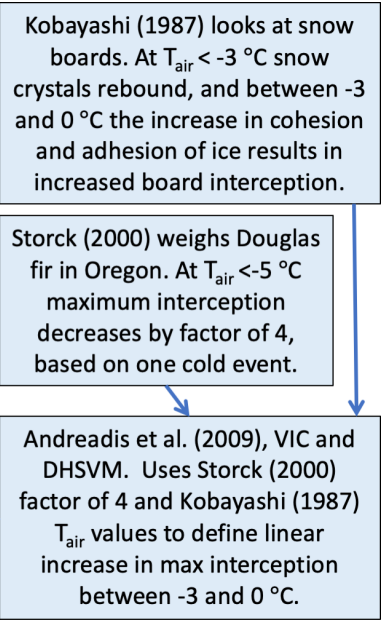

Kobayashi (1987) looks at snow boards. At $\mathrm{T}_{\text {air }}<-3^{\circ} \mathrm{C}$ snow ystals rebound, and between -3 d $0^{\circ} \mathrm{C}$ the increase in cohesion increased board interception.

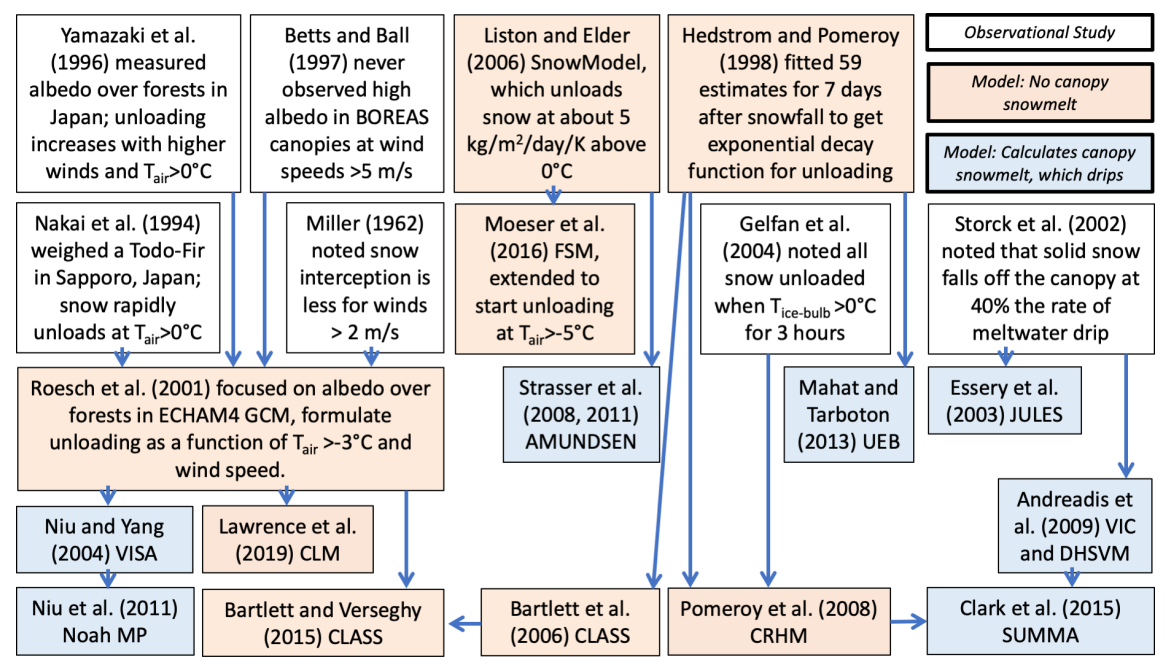



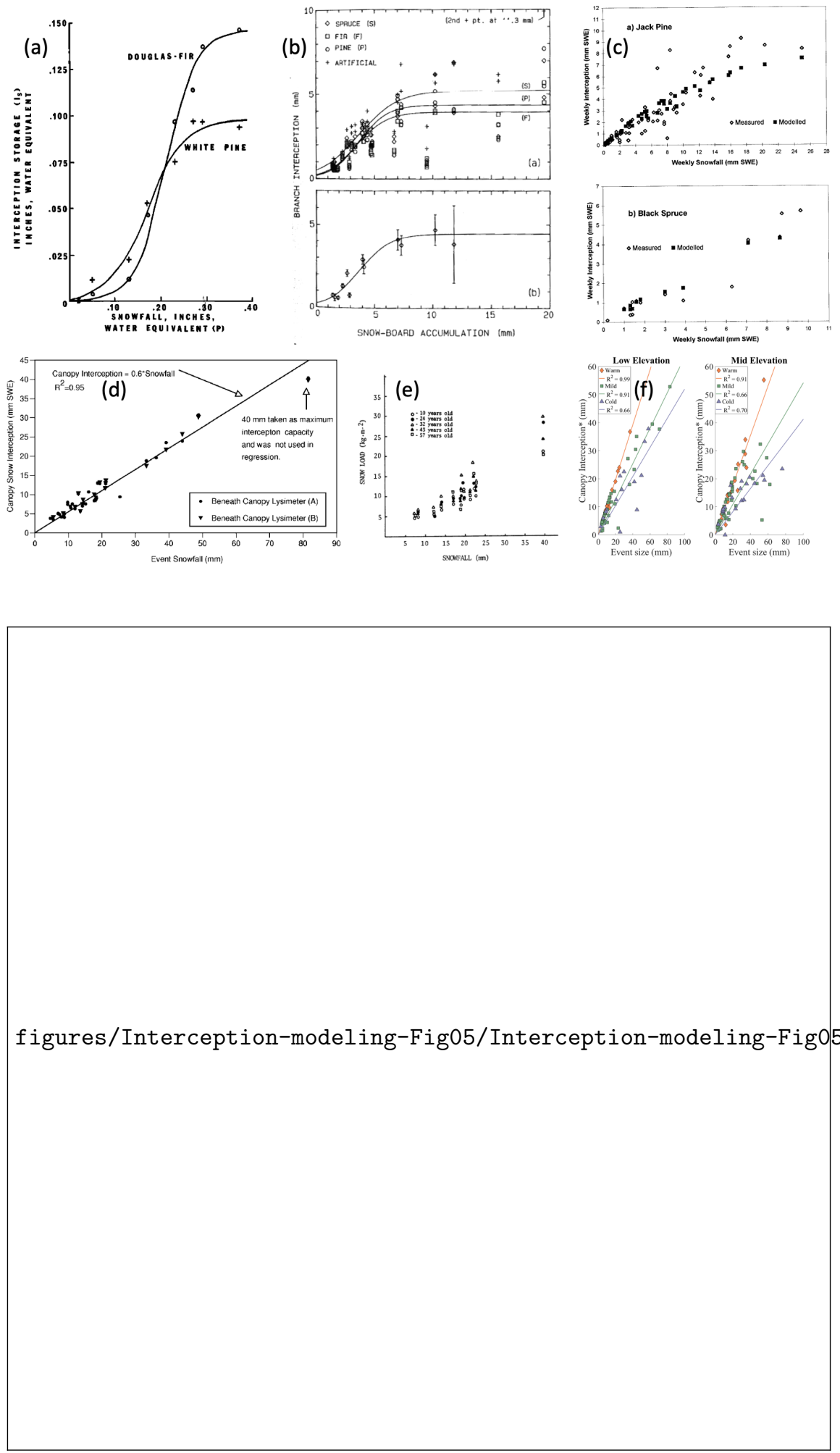
figures/Interception-modeling-Fig06/Interception-modeling-Fig06-eps-converted-to.pdf 
figures/Interception-modeling-Fig07/Interception-modeling-Fig07-eps-converted-to.pdf 
figures/Interception-modeling-Fig08/Interception-modeling-Fig08-eps-converted-to.pdf 